\title{
Ink From Longfin Inshore Squid, Doryteuthis pealeii, as a Chemical and Visual Defense Against Two Predatory Fishes, Summer Flounder, Paralichthys dentatus, and Sea Catfish, Ariopsis felis
}

\author{
CHARLES D. DERBY*, MIHIKA TOTTEMPUDI, TIFFANY LOVE-CHEZEM, AND \\ LANNA S. WOLFE \\ Neuroscience Institute and Department of Biology, Georgia State University, Atlanta, Georgia 30303; \\ and The Marine Biological Laboratory, Woods Hole, Massachusetts 02543
}

\begin{abstract}
Chemical and visual defenses are used by many organisms to avoid being approached or eaten by predators. An example is inking molluscs-including gastropods such as sea hares and cephalopods such as squid, cuttlefish, and octopus-which release a colored ink upon approach or attack. Previous work showed that ink can protect molluscs through a combination of chemical, visual, and other effects. In this study, we examined the effects of ink from longfin inshore squid, Doryteuthis pealeii, on the behavior of two species of predatory fishes, summer flounder, Paralichthys dentatus, and sea catfish, Ariopsis felis. Using a cloud assay, we found that ink from longfin inshore squid affected the approach phase of predation by summer flounder, primarily through its visual effects. Using a food assay, we found that the ink affected the consummatory and ingestive phase of predation of both sea catfish and summer flounder, through the ink's chemical properties. Fractionation of ink showed that most of its deterrent chemical activity is associated with melanin granules, suggesting that either compounds adhering to these granules or melanin itself are the most biologically active. This work provides the basis for a comparative approach to identify deterrent molecules from inking cephalopods and to examine neural mechanisms whereby these chemicals affect behavior of fish, using the sea catfish as a chemosensory model.
\end{abstract}

Received 29 August 2013; accepted 4 November 2013.

* To whom correspondence should be addressed. E-mail: cderby@ gsu.edu

Abbreviations: A, Accept; CMC, carboxymethylcellulose; $\mathrm{CMC}+\mathrm{dye}$, carboxymethylcellulose + dye; ER, Extraoral Reject; IR, Intraoral Reject.

\section{Introduction}

Anti-predatory defenses can be found in many forms throughout the animal kingdom, operating through a variety of sensory systems of predators, including olfactory, visual, and auditory (Ruxton et al., 2004; Caro, 2005; Eisner et al., 2007). Some molluscs use ink as a chemical defense against predators. Previous work on slow-moving inking molluscs — sea hares, Aplysia spp.—revealed a variety of molecules acting as chemical defenses through a variety of mechanisms (Derby, 2007; Derby and Aggio, 2011). One mechanism is the use of deterrent chemicals, either dietderived or synthesized de novo, that are aversive or unpalatable to predators (Aggio and Derby, 2008; Kamio et al., 2010, 2011; Nusnbaum and Derby, 2010a, b; Nusnbaum et al., 2012; Aggio et al., 2012). A second mechanism is phagomimicry, in which predators are distracted by attractive and appetitive compounds in the ink (Kicklighter et al., 2005). A third mechanism is sensory inactivation, in which the ink secretion partially blocks the activity of peripheral chemoreceptors of predators and thereby affects the predators' ability to detect and respond to appetitive cues (LoveChezem et al., 2013). The ink of sea hares also contains intraspecific alarm cues that evoke escape behaviors of conspecific sea hares, thus also functioning as an antipredatory chemical defense (Fiorito and Gherardi, 1990; Kicklighter et al., 2007, 2011). The diversity of defensive mechanisms allows sea hares to defend themselves against various species of predators (depending on the predators' sensitivity to the chemicals); against various individuals of a given species of predator (depending on the individual's physiological state, such as hunger); and in different envi- 
ronments (in the absence of foods containing diet-dependent chemical defenses). These mechanisms might also work in concert to be more effective than any one alone.

Cephalopods are also known to produce ink and use it defensively. Cephalopod ink is produced in and released from the ink sac, which is a modified hypobranchial gland rather than a homolog of the gastropod ink gland (Roseghini et al., 1996; Lindberg and Ponder, 2001). This raises an interesting question: Has a similar diversity of mechanisms of chemical defenses appeared through convergent evolution in the fast-moving inking cephalopods as in the slowmoving inking gastropods? Squid ink has often been thought to function mostly as a visual defense, in the form of a smoke screen or a distracting decoy (Lucero et al., 1994; Hanlon and Messenger, 1996; Norman, 2000; Caldwell, 2005; Bush and Robison, 2007). However, some reports describe several possible mechanisms. The first is as an intraspecific alarm cue, which causes conspecifics to produce escape behaviors such as jetting or inking (Gilly and Lucero, 1992; Lucero et al., 1994; Wood et al., 2008). A second mechanism is interspecific defense, based on the use of aversive, distasteful chemicals, as shown for ink of Caribbean reef squid Sepioteuthis sepioidea against a predatory fish, the French grunt Haemulon flavolineaum (Wood et al., 2010). The possibility that cephalopod ink functions as a phagomimetic defense has been considered because the ink of cephalopods contains millimolar concentrations of dissolved free amino acids (Derby et al., 2007) that are appetitive feeding stimuli for predatory fishes (Caprio and Derby, 2008). However, in the single test of this idea, using Caribbean reef squid and French grunts, no support was found (Wood et al., 2010). Some have proposed that cephalopod's mucousy ink may disrupt a predator's chemical senses (MacGinitie and MacGinitie, 1968; Fox, 1974; Kittredge et al., 1974; Prota et al., 1981; Moynihan and Rodaniche, 1982) in a way that may be similar to sensory inactivation by sea hares (Love-Chezem et al., 2013), but there is no published experimental evidence to support this claim.

In this study, we examined the effects of the ink of the longfin inshore squid (Doryteuthis pealeii) on two species of predatory fishes, the summer flounder (Paralichthys dentatus) and the sea catfish (Ariopsis felis). Summer flounder are sympatric with and voracious predators of longfin inshore squid (Staudinger and Juanes, 2010), making inking a behavior critical to higher survival rates (Staudinger et al., 2011). Sea catfish are active predators (Muncy and Wingo, 1983) with well-categorized olfactory and gustatory pathways (Michel and Caprio, 1991; Michel et al., 1993; Kohbara and Caprio, 1996; reviewed in Caprio and Derby, 2008) and are already used as an electrophysiological model of neural processing of sea hare inking chemical defenses (Sheybani et al., 2009; Nusnbaum et al., 2012). We aimed to determine if ink from the longfin inshore squid acts as a chemical or visual defense during the approach or consummatory phases of feeding by summer flounder and sea catfish. We also aimed to determine the chemical nature of the chemical defenses.

\section{Materials and Methods}

\section{Animals}

Inshore longfin squid, Doryteuthis (formerly Loligo) pealeii (Lesueur, 1821) (male and female, 15-45 cm), and summer flounder, Paralichthys dentatus (Linnaeus, 1766) (male and female, $30-45 \mathrm{~cm}$ ), were collected by the staff of the Marine Resources Center, Marine Biological Laboratory, Woods Hole, Massachusetts. They were kept in the Marine Resources Center in aquaria supplied with ambient flow-through seawater ranging from $16-20{ }^{\circ} \mathrm{C}$ and under natural lighting. Summer flounder were fed pieces of fresh squid daily, and squid were fed pieces of frozen fish daily. Experiments on summer flounder were performed in an aquarium $300-\mathrm{cm}$ long $\times 100-\mathrm{cm}$ wide $\times 30$ - $\mathrm{cm}$ high. Sea catfish, Ariopsis felis (Linnaeus 1766) (male and female, $10-30 \mathrm{~cm}$ ), were purchased from Gulf Specimen Marine Laboratory, Panacea, Florida. They were maintained at Georgia State University in individual 40-liter glass aquaria (50-cm long $\times 25-\mathrm{cm}$ wide $\times 30$-cm high) containing recirculating, filtered, and aerated artificial seawater (Instant Ocean, Aquarium Systems, Mentor, $\mathrm{OH}$ ) at a salinity of $28 \%$ under a 12:12 light/dark cycle. They were fed frozen shrimp. Experiments were performed in these same aquaria. The care and use of animals was approved by the Institutional Animal Care and Use Committee at Georgia State University and the Marine Biological Laboratory.

\section{Chemicals}

Squid ink. Ink sacs were collected from freshly killed squid. Ink was gently squeezed from ink sacs and stored at full strength at $-80{ }^{\circ} \mathrm{C}$ until used in experiments. Dilutions of whole squid ink were centrifuged at $14,000 \times g$ for $15 \mathrm{~min}$ at $4{ }^{\circ} \mathrm{C}$, yielding a pellet containing melanin granules and other particulates in whole ink and a supernatant containing a fraction that is free of melanin granules and other particulates.

Carboxymethylcellulose. Carboxymethylcellulose (CMC) was tested to mimic the physical consistency of squid ink in experiments with summer flounder. CMC was prepared by mixing $3 \mathrm{~g}$ of carboxymethylcellulose (\#C-5013, SigmaAldrich, St. Louis, MO) in $50 \mathrm{ml}$ of seawater to produce a mixture with the consistency of squid ink.

Dye. A food-color-based dye was tested on summer flounder to mimic the color of squid ink. We used McCormick Black food color (McCormick and Co., Inc., Sparks, MD), 
diluted to mimic the color and intensity of the various dilutions of squid ink.

Carboxymethylcellulose + dye. Carboxymethylcellulose + dye $(\mathrm{CMC}+\mathrm{dye})$ was tested to mimic both the consistency and visual appearance of squid ink but without the chemical components. The concentrations of the two components were the same as when tested individually.

Seawater. Seawater (SW) was used as a control stimulus. Natural seawater was used for summer flounder, and artificial seawater (Instant Ocean) was used for sea catfish.

Quinine. Quinine hydrochloride was tested at 10 to $40 \mathrm{mmol}$ $1^{-1}$ (Sigma-Aldrich) as a positive control, as it is known to be deterrent to some fish (Funakoshi et al., 1981; Lamb and Finger, 1995; Ogawa et al., 1997).

Sea hare ink. Secretion from the ink glands of wild-caught California sea hares, Aplysia californica Cooper, 1863, was collected as described elsewhere (e.g., Kicklighter et al., 2005; Yang et al., 2005). Sea hare ink was tested at $1 \%$ of full strength as a positive control and also to determine the relative degree of deterrence of squid ink, since sea hare ink is highly unpalatable to many species of fish (Nusnbaum and Derby, 2010a, b; Nusnbaum et al., 2012).

\section{Assays}

Two assays were used to examine the effects of squid ink on two phases of the feeding behavior of fish. A cloud assay was used to examine the approach phase, and a food assay was used to examine the consumption phase. All behavior was video-recorded, and data were collected and analyzed from recordings or directly from observations.

Cloud assay. This assay was used to determine if squid ink affects the approach phase of feeding behavior of summer flounder. This assay is generally similar to an assay previously used on French grunts Haemulon flavolineaum (Wood et al., 2010) and blue head wrasse Thalassoma bifasciatum (Nusnbaum and Derby, 2010b). In this assay, squid ink and other treatments were presented as a "cloud" while the flounder approached a piece of food. Several flounder were acclimated in a $300-\mathrm{cm}$ long $\times 100-\mathrm{cm}$ wide $\times 30-\mathrm{cm}$ high aquarium equipped with filtered, flow-through seawater. Testing of a flounder consisted of presenting squid tentacles as food about $1 \mathrm{~m}$ from the flounder, using a pipette modified to have a small hook at the end to loosely hold the squid. As the flounder began its approach and was about 20 $\mathrm{cm}$ from the food, $1 \mathrm{ml}$ of one of several treatments was pipetted into the water between the food and the flounder. The cloud was approximately $4 \mathrm{~cm}$ in diameter when first introduced. Treatments were the following: (1) squid ink diluted to $20 \%$ full strength in SW; (2) CMC+dye, to simulate the texture and visual appearance of squid ink; (3) $\mathrm{SW}$, as a control for the medium in which the previous two treatments were mixed; and (4) nothing, where the pipette was introduced into the aquarium but no treatment was ejected from the pipette. All four treatments were tested twice, with each set of four treatments tested in a block in random order with at least $30 \mathrm{~min}$ between tests. After each experiment, each flounder was fed to satiation. There were one or two days between testing each block of four treatments. We attempted to present stimuli and analyze responses to them in a blind fashion, but because of differences in the color of some stimuli, the blind procedure was not possible for all stimuli.

All trials were video-recorded (Sony camera) to calculate the approach time, defined as the time from the flounder's first motion toward the food until the flounder took the food into its mouth. Each flounder was given a total of $30 \mathrm{~s}$ to consume the food after the treatment was injected into the tank. A Friedman's test followed by one-tailed Wilcoxon matched-pairs post hoc tests were used to determine if experimental treatments (squid ink or $\mathrm{CMC}+$ dye) significantly increased approach time compared to controls (SW or nothing).

Food assay. This assay was designed to test the palatability of squid ink to summer flounder and sea catfish. It was performed in a similar fashion to our previous procedures with fish (Nusnbaum and Derby, 2010a, b; Nusnbaum et al., 2012) and as commonly used by others to test deterrence of natural products against predatory fishes (e.g., Pawlik, 1993; Kubanek et al., 2000).

\section{Summer flounder}

For summer flounder, five types of pellets were made: four types were flavored with food, and one was unflavored. The food flavoring was squid juice, made by cutting the mantle of freshly dead squid into pieces, soaking in seawater for $3 \mathrm{~h}$, filtering, then storing the filtrate at $-80^{\circ} \mathrm{C}$ until used to make a pellet mixture. The pellet mixture was created by adding $3 \mathrm{ml}$ of squid juice to $0.6 \mathrm{~g}$ of alginate powder (Sigma) and $40 \mathrm{ml}$ of distilled water; then this was mixed with one of four treatments by drawing the pellet mixture + treatment into a $3-\mathrm{ml}$ syringe and extruding it into $0.25 \mathrm{~mol} \mathrm{l}^{-1} \mathrm{CaCl}_{2}$. The four treatments for the foodflavored pellets were $10 \%$ squid ink, $10 \mathrm{mmol}^{-1}$ quinine, dye, and SW. The unflavored pellet type had $3 \mathrm{ml}$ of SW instead of squid juice, and it was used only with a treatment of $10 \%$ squid ink. Preliminary results with the fish species used in this study as well as other fish species in our past work show that the food-flavored pellets are palatable to fish and are consumed, but that the unflavored pellets are not. The unflavored pellets treated with squid ink were used to 
Cloud Assay for Summer Flounder $(n=10)$

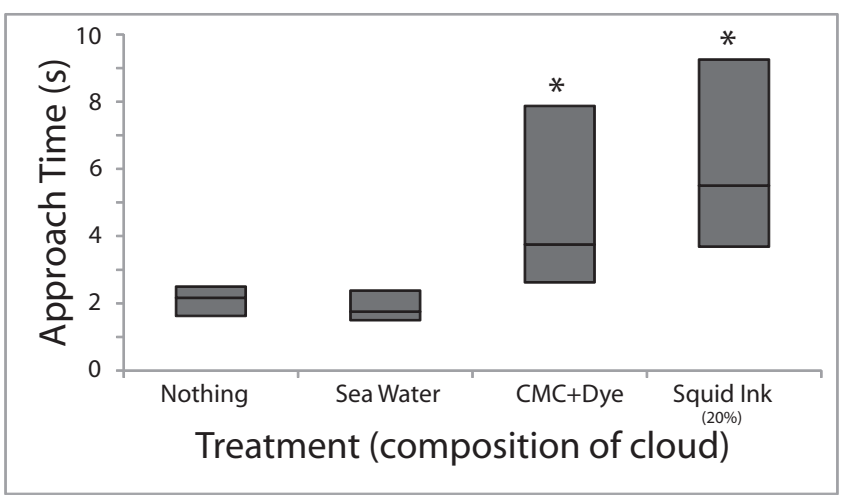

Figure 1. Cloud Assay for Summer Flounder. Values for approach times are median \pm interquartile range for 10 flounder. A Friedman test shows a significant treatment effect, and Wilcoxon matched-pair signedranks tests $(\alpha=0.05)$ show a significant difference between controls (seawater or nothing) and either squid ink (20\% full strength) or $\mathrm{CMC}+$ dye (indicated by an asterisk), but no significant difference between squid ink and $\mathrm{CMC}+$ dye.

test if addition of squid ink made these pellets palatablethat is, if squid ink is a phagomimic. A clear plastic rod was used to present pellets to fish. All treatments were tested twice, with each set of treatments presented in a block in random order with at least $30 \mathrm{~min}$ between tests. After each experiment, each flounder was fed to satiation. There were one or two days between testing each block of treatments. To be counted as a trial, fish had to contact the pellet, and no data for the day were used unless a food-flavored pellet was accepted that day.

Three behaviors toward pellets were observed: Accept (A), in which the pellet was eaten and did not reappear within $10 \mathrm{~min}$; Intraoral Reject (IR), in which the pellet was taken into the mouth and at least half was expelled from the mouth; and Extraoral Reject (ER), in which the pellet was touched but not taken into the mouth. We used $\mathrm{A}$ as a positive measure of palatability. Conversely, we used IR and ER as negative measures of palatability, with ER considered a more intense form of rejection, since animals performing ER rejected the food after having touched it but without taking it into the mouth for further sampling. For quantification of palatability of pellet, we used an Unpalatability index, ranging from 0 to 2 , in which A was scored 0 , IR was scored 1, and ER was scored 2. Each of the 10 flounder used in the study was tested twice with each treatment, and an Unpalatability index value was calculated for each treatment and for each fish by taking the mean of the two trials. Evaluation of differences between the treatments was made using a repeated-measure one-way ANOVA, followed by post hoc LSD tests $(\alpha=0.05)$ to compare the SW control treatment versus each of the other treatments. For each treatment, the frequency of the three types of response (A:IR:ER) out of the total number of trials was compared, and these distributions were compared across treatments using contingency tables.

\section{Sea catfish}

For sea catfish, the food assay was similar but with some modifications. Instead of using food-flavored alginate pellets as a palatable food into which squid ink and other treatments could be added to assess deterrence, freeze-dried shrimp were used as food. Shrimp were purchased at local food stores, soaked in SW for $3 \mathrm{~h}$ to lessen their attractiveness by leaching out appetitive chemicals, freeze-dried, then cut into pieces of about $2 \mathrm{~cm} \times 0.5 \mathrm{~cm}$.

Ten treatments were tested on sea catfish, including seven experimental treatments involving squid ink, and three controls. The experimental treatments were whole squid at $10 \%$ full strength, and the pellet and supernatant of centrifuged ink (prepared as described above), each tested at 10\%, 20\%, and $50 \%$ full strength. The three control treatments included two positive controls $\left(10-40 \mathrm{mmol}^{-1}\right.$ quinine and $1 \%$ sea hare ink, both known to be deterrent for this and other fish species (Nusnbaum and Derby, 2010a; Nusnbaum et al., 2012)), and one negative control (SW).

A $0.5-\mathrm{ml}$ aliquot of one of 10 treatments was then added directly to the freeze-dried shrimp. The shrimp completely absorbed the treatment. Pieces of shrimp were attached to a small rod fashioned into a hook and presented to the sea catfish by touching the food to the fish's barbels. Pieces of SW-treated shrimp were fed to fish after each trial as a positive control, and data for a trial were not used if the fish did not accept this control. Time between presentations of pieces of shrimp was at least $20 \mathrm{~min}$. Examples for sea catfish of A behavior to shrimp treated with SW and ER behavior to shrimp treated with quinine are shown in supplemental videos 1 and 2 respectively (http://www.biolbul1.org/content/supplemental).

Data from 18 sea catfish were included in the data analysis, though not every fish received all treatments, and thus the sample sizes for the treatments ranged from 6 to 16. An ANOVA with post hoc LSD tests was used to compare responses to the seawater control treatment versus each of the other treatments. As for summer flounder, the frequencies of the three types of response (A:IR:ER) out of the total number of trials for each treatment were calculated, and these distributions were compared by using contingency tables.

\section{Results}

\section{Summer flounder}

Cloud assay. A cloud assay was used to assess how the presence of squid ink affects the behavior of flounder as they move toward a piece of food. Median values of approach times for the four treatments were squid ink, $5.50 \mathrm{~s}$; 


\section{Food Assay for Summer Flounder $(n=10)$}

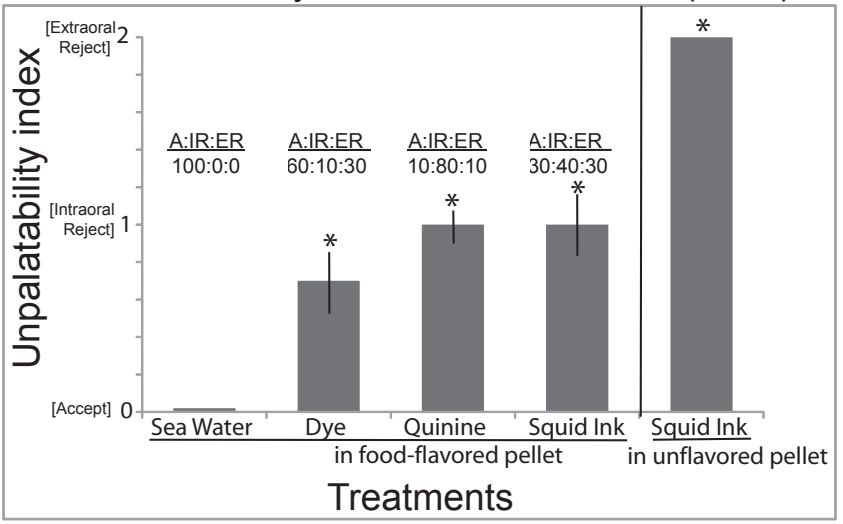

Figure 2. Food Assay for Summer Founder. Unpalatability index values are means \pm S.E.M. for 10 flounders. A repeated measure one-way ANOVA with post hoc LSD test shows that the Unpalatability index value for food-flavored alginate pellets with seawater was significantly less that for food-flavored pellets with either squid ink (10\% full strength), quinine $\left(10 \mathrm{mmol}^{-1}\right)$, or dye, or for the squid ink pellets lacking food flavoring. The frequencies of Accept : Intraoral Reject : Extraoral Reject (A:IR:ER) for all the trials for each treatment are given above the bars.

CMC+dye, 3.75 s; nothing, $2.17 \mathrm{~s}$; and SW, $1.75 \mathrm{~s}$ (Fig. 1). There was a significant treatment effect (Friedman ANOVA, chi-square $=22.82, n=10, \mathrm{df}=3, P<$ $0.00004)$; and post hoc testing with Wilcoxon matchedpairs signed-ranks tests $(\alpha=0.05)$ showed that two treatments, squid ink and $\mathrm{CMC}+$ dye, had significantly longer approach times than either of the negative controls, SW or nothing. Furthermore, there was no difference in the approach times for squid ink versus $\mathrm{CMC}+$ dye. These results show that squid ink released between a flounder and its food delays approaches, and suggest that the effect is due to visual effects more than chemical.

Food assay. A food assay was used to determine if squid ink affects the palatability of food for summer flounder. The mean value for the Unpalatability index for the food-flavored alginate pellets with control (SW) was 0 , showing that all fish ate all of these pellets (Fig. 2). The mean Unpalatability index values for the other three treatments with food-flavored pellets were squid ink, 1.0; quinine, 1.0; and dye, 0.70 (Fig. 2). The mean Unpalatability index value for alginate pellets with squid ink but lacking food flavoring was 2.0. A repeated-measure one-way ANOVA shows that these five treatments are significantly different $\left(F_{[4,36]}=\right.$ 43.57, $P=0.000001)$. Post hoc LSD tests $(\alpha=0.05)$ show that the Unpalatability index value for food-flavored pellets with either squid ink, quinine, or dye was significantly greater than for the negative control, food-flavored pellets with SW. Thus, squid ink added to food significantly reduced the palatability of that food, as did the positive control, quinine. Dye added to the food-flavored pellets also significantly increased the unpalatability of the food compared to the SW control.

Examination of the frequencies of Accept, Intraoral Reject, and Extraoral Reject (A:IR:ER) helped to elucidate mechanisms underlying the Unpalatability index values presented above. The A:IR:ER frequencies for the five treatments are shown above the bars in Figure 2, and these frequencies are significantly different from each other $(3 \times 5$ contingency table, chi-square $=105.0, \mathrm{df}=8, P<0.0001$ ). The A:IR:ER frequencies for the SW control (100:0:0) were, as expected, different from each of the other treatments, since all flounder accepted all of these pellets. While the Unpalatability index values for quinine (1.0), squid ink (1.0), and dye (0.70) were similar (Fig. 2), their A:IR:ER frequencies were significantly different (Fig. 3) $(2 \times 3$ contingency tables, $P<0.05$ ). Thus, even though food-flavored pellets with squid ink or quinine were rejected with about the same frequency ( $90 \%$ vs. $70 \%$ rejection), quinine pellets were two times more likely than squid ink pellets to be taken into the mouth and then rejected $(80 \%$ vs. $40 \%)$. The A:IR:ER frequency distribution for dye (60:10:30) was different from that for either squid ink or quinine, but the frequency of ER for dye and squid ink was similar (30\%) and three times higher than for quinine $(10 \%)$. Together these results suggest that both chemical and visual features of squid ink contribute to its effects in this assay.

Squid ink embedded in plain alginate pellets (that is, pellets not containing food flavoring) were not eaten by flounder (right bar of Fig. 2) and were all rejected without

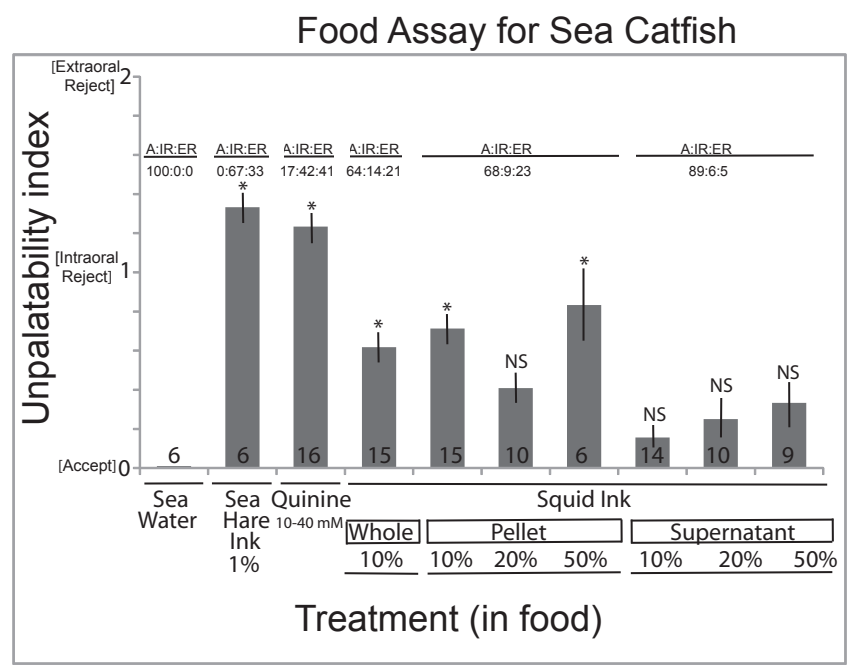

Figure 3. Food Assay for Sea Catfish. Unpalatability index values are means \pm S.E.M. for the number of animals given at the bottom of each bar. An ANOVA with post hoc LSD tests shows that the Unpalatability index values for the treatments differ, with those treatments significantly different from seawater indicated by an asterisk, and those treatments not significantly different from seawater indicated by NS. The frequencies of Accept : Intraoral Reject : Extraoral Reject (A:IR:ER) for all the trials for each treatment are given above the bars. 
being taken into the mouth (i.e., $100 \% \mathrm{ER}$ ), similar to plain pellets without squid ink. These results show that squid ink itself is not palatable to flounder and thus that phagomimicry is not a mechanism of chemical defense for squid ink.

\section{Sea catfish}

Food assay. For the food assay with sea catfish, we tested shrimp flavored with one of 10 treatments. An ANOVA showed a significant difference in the Unpalatability index values across these 10 treatments $\left(F_{[9,96]}=5.00, P=\right.$ 0.00002). Post hoc LSD tests showed that shrimp treated with either of two positive controls, $10-40 \mathrm{mmol} \mathrm{l}^{-1}$ quinine or $1 \%$ sea hare ink, had Unpalatability index values significantly greater than did shrimp treated with the negative control, SW (Fig. 3). Shrimp treated with SW were eaten by all animals (Unpalatability index value of 0 ), and the Unpalatability index values for SW, sea hare ink, and quinine were $0,1.33$, and 1.23 , respectively. Shrimp treated with $10 \%$ squid ink had an Unpalatability index value of 0.62 , which was significantly greater than the SW control, though half that of the positive controls.

Toward identifying the nature of the chemical deterrents in squid ink, we tested two fractions of squid ink separated by centrifugation: a fraction containing melanin and other particulates ("pellet") and the remainder ("supernatant"). For each of these two fractions, we tested three concentrations: $10 \%, 20 \%$, and $50 \%$ full strength squid ink. Unpalatability index values for two of the three concentrations of squid ink pellet were significantly greater than for the SW control ( 0.71 for $10 \%$ and 0.83 for $50 \%$ ); the value for $20 \%$ squid ink pellet was 0.41 . Unpalatability index values for the three concentrations of the squid ink supernatant- 0.16 for $10 \%, 0.25$ for $20 \%$, and 0.33 for $50 \%$-were all less than the values for the pellet fraction, and none were significantly different from the SW control. Thus, squid ink is unpalatable to sea catfish, though not as much as is sea hare ink, and most of the bioactivity is in the pellet fraction containing melanin. The A:IR:ER frequencies also differ for these treatments $(10 \times 3$ contingency table, chi square $=$ 117.0, df $=18, P<0.0001)$. However, this is due to differences in the acceptance versus rejection rates rather than to differences between the two types of rejection $(10 \times 2$ contingency table with only the two types of rejection, chi square $=13.9, \mathrm{df}=9, P>0.05)$.

\section{Discussion}

Two species of predatory fishes-summer flounder, Paralichthys dentatus, and sea catfish, Ariopsis felis-were used to evaluate whether ink from longfin inshore squid, Doryteuthis pealeii, is a chemical defense. Summer flounder are voracious, sympatric predators of longfin inshore squid in their natural environment (Staudinger and Juanes, 2010). Inking by longfin inshore squid is associated with increased survival during staged encounters in laboratory aquaria (Staudinger et al., 2011). In addition, summer flounder are highly visual predators in encounters with squid (Staudinger et al., 2011). Thus, we chose the summer flounder as a natural and proven predator of longfin inshore squid and one for which vision plays a dominant role. Sea catfish are active predators and can encounter and eat squid in their natural environment, though sea catfish are not sympatric with longfin inshore squid (Muncy and Wingo, 1983). Sea catfish were used because they and their ictalurid relatives use their chemical senses-olfaction, external taste via their barbels, and internal taste-in locating and orienting to food from a distance, and upon contact deciding whether or not to take it into the mouth and swallow (Caprio et al., 1993; Sorensen and Caprio, 1998; Caprio and Derby, 2008). Furthermore, sea catfish are a proven experimental model for understanding the functional organization of the chemical senses, including neural processing of ink defenses of sea hares (Michel and Caprio, 1991; Michel et al., 1993; Kohbara and Caprio, 1996; Caprio and Derby, 2008; Sheybani et al., 2009; Nusnbaum et al., 2012), which makes them valuable for neuroethological studies such as ours.

Our results support the idea that ink protects longfin inshore squid from predatory fish through multimodal effects. First, ink from the longfin inshore squid affected the approach phase of feeding behavior of predatory summer flounder by delaying the time to reach food. However, there was no significant difference in approach time for a cloud of ink compared with a cloud of dye, suggesting that the protective effect of ink is visual. This is further supported by the fact that predatory strikes of summer flounder on squid are quick and visually guided (Staudinger et al., 2011; Derby, pers. obs.). A similar effect was seen for French grunts, Haemulon flavolineatum, another visual predatory fish, in which either a cloud of ink from the Caribbean reef squid or a cloud of dye delayed approaches (Wood et al., 2010). However, it should be noted that our methods do not allow us to conclusively exclude the possibility that the effects of dye in the cloud assay are from interaction of dye chemicals with the olfactory sense of the predator, especially since this dye is unpalatable to summer flounder (food assay, Fig. 2). The dye, McCormick Black food color, consists of FD\&C colors Red 40, Blue 1, Yellow 5, phosphoric acid, sodium benzoate (as preservative), and water. In previous work (Wood et al., 2008, 2010), a different food color-a mixture of McCormick food colors Red, Blue, and Green-was unpalatable to French grunts (Wood et al., 2010). The mixture of Red, Blue, and Green contains three ingredients also present in our McCormick Black food color-Red 40, Blue 1, Yellow 5-but it contains three components not in Black food color-Red 3, propylene glycol, and propylparaben; it also lacks two components present in Black food color-phosphoric acid and sodium benzoate. Wood et al. (2010) hypothesized that propylpara- 
ben, a preservative, was unpalatable to French grunt because propylparaben is also aversive to the squid Doryteuthis opalescens, causing this squid to produce escape jetting (Gilly and Lucero, 1992). So, in the current study, we used a different dye, McCormick Black, since it lacks propylparaben. However, given that McCormick Black is unpalatable to summer flounder, it may be that one or more of the food colors common to both our dye and the Red, Blue, and Green mixture (i.e., Red 40, Blue 1, and/or Yellow 5) causes the unpalatability. It is also possible that both sodium benzoate and propylparaben are aversive. In any case, given the unpalatability of the dye in the food assay, we cannot be sure if the effect of the dye in the cloud assay with summer flounder is due to its visual or chemical properties.

Second, ink from longfin inshore squid affected the ingestion of food by both summer flounder and sea catfish. In the food assay, squid ink incorporated into food decreased the palatability of that food for summer flounder and sea catfish, such that they were less likely to take it into the mouth once touched and less likely to swallow the food. This effect was also seen with ink from Caribbean reef squid tested on French grunt (Wood et al., 2010). Ink from another inking mollusc-sea hares (Aplysia spp.) - is also unpalatable and affects predatory sea anemones (Nolen $e t$ al., 1995; Kicklighter and Derby, 2006), crustaceans (Kicklighter et al., 2005; Kamio et al., 2010; Derby and Aggio, 2011; Aggio et al., 2012), and fish (Nusnbaum and Derby, 2010a, b; Nusnbaum et al., 2012). Our work here shows that squid ink is unpalatable to sea catfish but not nearly as much as ink from sea hares, with $1 \%$ sea hare ink causing all fish to reject shrimp while $10 \%$ squid ink caused rejection in only $36 \%$ of encounters. The fact that the squid ink is less effective as a chemical defense compared to sea hare ink might be expected for two reasons. First, given that squid are very fast swimmers, even a weak chemical defense that provides a brief delay in approach is sufficient to enable escape from predatory fish. Second, sea hares acquire many defensive compounds or their precursors from their herbivorous diet (Avila, 1995; Cimino et al., 1999; Kamiya et al., 2006). Squid are predators and therefore do not ingest these compounds.

We did not find evidence that squid ink is effective as a phagomimetic chemical defense. Sea hare ink can protect against predatory spiny lobsters by virtue of its high millimolar concentrations of dissolved free amino acids (Derby et al., 2007). These compounds at high doses are feeding stimulants to spiny lobsters, and consequently sea hares can use their ink as a phagomimic to misdirect the attack of spiny lobsters away from the sea hare itself and toward the ink (Kicklighter et al., 2005). Squid ink contains low millimolar doses of amino acids (Derby et al., 2007) and as such has the potential to be a phagomimetic to the many species of fish for which amino acids are feeding stimulants (Carr $e t$ al., 1996; Derby and Sorensen, 2008). However, our results here with summer flounder and previous results with French grunt (Wood et al., 2010) did not find that squid ink has any appetitive action by itself: it was not accepted by fish when presented in an alginate pellet without food flavoring. Thus squid ink does not appear to act through phagomimicry against these predatory fishes.

Our results extend our understanding of the use of ink by squid as a chemical defense against predatory fish by partially identifying the nature of the active chemicals. For sea catfish, the unpalatable chemicals in squid ink are associated with particulates that are separated by centrifugation of ink. This fraction includes but is not limited to melanin, raising the possibility that the defensive compounds could be either melanin itself or compounds adhering to or associated with melanin. For example, it is known that dopamine adsorbs onto melanin granules of ejected cuttlefish ink (Fiore et al., 2004). The bioactive fraction of squid ink also includes particulates besides melanin, and these could be the source of the chemical deterrents. Future studies using bioassayguided fractionation will be necessary to identify the bioactive molecules in the melanin-containing fraction of squid ink.

It is also important to note that squid ink is generally thought to be composed of two secretions. One is the black ink produced by the ink gland and stored in and released from the ink sac, as we used in our study. A second is the mucus secreted by the funnel organ, also called Verrill's organ (Laurie, 1888; Williams, 1909; Fioroni, 1962; Voss, 1963; Hu et al., 2010). The combination of these two secretions is thought to allow squid to produce ink of various consistencies, ranging from a diffuse cloud to a substantive pseudomorph (Boletsky, 1997; Young and Mangold, 2000; Bush and Robison, 2007). In our current study, we tested only the ink sac secretion, as our ink collections were from dissected animals and we could not find substantial amounts of mucus in the funnel organ. Thus, it is possible that ink naturally released by $D$. pealeii will have effects on fish in addition to those that we identified, but exploring these will depend on being able to collect sufficient quantities of the mucus from funnel organs.

\section{Acknowledgments}

Experimental protocols were approved through Institutional Animal Care and Use Committees of Georgia State University and the Marine Biological Laboratory. We thank Dr. Scott Lindell and the staff of the Marine Resources Center of the Marine Biological Laboratory for research space and support, Dr. Joshua Hamilton and Julie Early for administrative support at the Marine Biological Laboratory, and Dr. Roger Hanlon and his research team at the Program in Sensory Physiology \& Behavior of the Marine Biological Laboratory for advice, discussion, technical assistance, and 
logistical support. Our project was supported by National Science Foundation grant IOS-1036742 and REU supplements IOS-1338385, IOS 1234038, and IOS-1130244; by The Plum Foundation John E. Dowling Fellowship Fund and the Colwin Endowed Summer Research Fellowship Fund from the Marine Biological Laboratory; and by a Second Century Initiative graduate fellowship from Georgia State University. We also thank Vivian Ngo-Vu and Drs. Juan Aggio and Manfred Schmidt at Georgia State University for assistance with experiments, and Dr. Schmidt and Sarah Miller for critical comments on a draft of the manuscript.

\section{Literature Cited}

Aggio, J. F., and C. D. Derby. 2008. Hydrogen peroxide and other components in the ink of sea hares are chemical defenses against predatory spiny lobsters acting through non-antennular chemoreceptors. J. Exp. Mar. Biol. Ecol. 363: 28-34.

Aggio, J. F., R. Tieu, A. Wei, and C. D. Derby. 2012. Oesophageal chemoreceptors of blue crabs, Callinectes sapidus, sense chemical deterrents and can block ingestion of food. J. Exp. Biol. 215: 17001710.

Avila, C. 1995. Natural products of opisthobranch molluscs: a biological review. Oceanogr. Mar. Biol. Апnи. Rev. 33: 487-559.

Boletsky, S. von. 1997. Puffing smoke-rings underwater: the functional morphology of cephalopod ink ejectors. Vie Milieu 471: 180-181.

Bush, S. L., and B. H. Robison. 2007. Ink utilization by mesopelagic squid. Mar. Biol. 152: 485-494.

Caldwell, R. L. 2005. An observation of inking behavior protecting adult Octopus bocki from predation by green turtle (Chelonia mydas) hatchlings. Pac. Sci. 59: 69-72.

Caprio, J., and C. D. Derby. 2008. Aquatic animal models in the study of chemoreception. Pp. 97-134 in The Senses: A Comprehensive Reference, Vol. 4, Olfaction \& Taste, S. Firestein and G. K. Beauchamp, eds. Academic Press, San Diego.

Caprio, J., J. G. Brand, J. H. Teeter, T. Valentinčič, D. L. Kalinoski, J. Kohbara, T. Kumazawa, and S. Wegert. 1993. The taste system of the channel catfish: from biophysics to behavior. Trends Neurosci. 16: $192-197$.

Caro, T. 2005. Antipredator Defenses in Birds and Mammals. University of Chicago Press, Chicago, IL.

Carr, W. E. S., J. C. Netherton III, R. A. Gleeson, and C. D. Derby. 1996. Stimulants of feeding behavior in fish: analyses of tissues of diverse marine organisms. Biol. Bull. 190: 149-160.

Cimino, G., A. Fontana, and M. Gavagnin. 1999. Marine opisthobranch molluscs: chemistry and ecology in sacoglossans and dorids. Curr. Org. Chem. 3: 327-372.

Derby, C. D. 2007. Escape by inking and secreting: marine molluscs avoid predators through a rich array of chemicals and mechanisms. Biol. Bull. 213: 274-289.

Derby, C. D., and J. Aggio. 2011. Neuroecology of chemical defenses. Integr. Comp. Biol. 51: 771-780.

Derby, C. D., and P. W. Sorensen. 2008. Neural processing, perception, and behavioral responses to natural chemical stimuli by fish and crustaceans. J. Chem. Ecol. 34: 898-914.

Derby C. D., C. E. Kicklighter, P. M. Johnson, and X. Zhang. 2007. Chemical composition of diverse marine molluscs suggests convergent chemical defenses. J. Chem. Ecol. 33: 1105-1113.

Eisner, T., M. Eisner, and M. Siegler. 2007. Secret Weapons: Defenses of Insects, Spiders, Scorpions, and Other Many-Legged Creatures. Belknap Press of Harvard University Press, Cambridge, MA.
Fiore, G., A. Poli, A. Di Cosmo, M. d'Ischia, and A. Palumbo. 2004. Dopamine in the ink defense system of Sepia officinalis: biosynthesis vesicular compartmentation in mature ink gland cells, nitric oxide (NO)/cGMP-induced depletion and fate in secreted ink. Biochem. $J$ 378: 785-791.

Fiorito, G., and F. Gherardi. 1990. Behavioural changes induced by ink in Aplysia fasciata (Mollusca, Gastropoda): evidence for a social role of inking. Mar. Behav. Physiol. 17: 129-135.

Fioroni, P. 1962. Die embryonale Entwicklung der Hautdrüsen und des Trichterorganes von Octopus vulgaris Lam. Acta Anat. 50: 264-295.

Fox, D. L. 1974. Biochromes: occurrence, distribution and comparative biochemistry of prominent natural pigments in the marine world. Pp. 169-211 in Biochemical and Biophysical Perspectives in Marine Biology, Vol. 1, D. C. Malins and J. R. Sargent, eds. Academic Press, New York.

Funakoshi, M., K. Kawakita, and T. Marui. 1981. Taste response in the facial nerve of the carp, Cyprinus carpio L. Jpn. J. Physiol. 31: 381-390.

Gilly, W. F., and M. T. Lucero. 1992. Behavioral responses to chemical stimulation of the olfactory organ in the squid Loligo opalescens. J. Exp. Biol. 162: 209-229.

Hanlon, R. T., and J. B. Messenger. 1996. Cephalopod Behaviour Cambridge University Press, Cambridge.

Hu, M. Y., E. Sucré, M. Charmantier-Daures, G. Charmantier, M. Lucassen, N. Himmerkus, and F. Melzner. 2010. Localization of ion-regulatory epithelia in embryos and hatchlings of two cephalopods. Cell Tissue Res. 339: 571-583.

Kamio, M., T. V. Grimes, M. H. Hutchins, R. van Dam, and C. D. Derby. 2010. The purple pigment aplysioviolin in sea hare ink deters predatory blue crabs through their chemical senses. Anim. Behav. 80: 89-100.

Kamio, M., C. E. Kicklighter, L. Nguyen, M. W. Germann, and C. D. Derby. 2011. Isolation and structural elucidation of novel mycosporine-like amino acids as alarm cues in the defensive ink secretion of the sea hare Aplysia californica. Helv. Chim. Acta 94: 1012-1018.

Kamiya, H., R. Sakai, and M. Jimbo. 2006. Bioactive molecules from sea hares. Pp. 215-239 in Molluscs: From Chemo-Ecological Study to Biotechnological Application, G. Cimino and M. Gavagnin, eds. Progress in Molecular and Subcellular Biology 43, Springer, Berlin.

Kicklighter, C. E., and C. D. Derby. 2006. Multiple components in ink of the sea hare Aplysia californica are aversive to the sea anemone Anthopleura sola. J. Exp. Mar. Biol. Ecol. 334: 256-268.

Kicklighter, C. E., S. Shabani, P. M. Johnson, and C. D. Derby. 2005. Sea hares use novel antipredatory chemical defenses. Curr. Biol. 15: $549-554$

Kicklighter, C. E., M. W. Germann, M. Kamio, and C. D. Derby. 2007. Molecular identification of alarm cues in the defensive secretions of the sea hare Aplysia californica. Anim. Behav. 74: 1481-1492.

Kicklighter, C. E., M. Kamio, L. Nguyen, M. W. Germann, and C. D. Derby. 2011. Mycosporine-like amino acids are multifunctional molecules in sea hares and their marine community. Proc. Natl. Acad. Sci. USA 108: 11494-11499.

Kittredge, J. S., F. T. Takahashi, J. Lindsey, and R. Lasker. 1974. Chemical signals in the sea: marine allelochemics and evolution. Fish. Bull. 72: 1-11.

Kohbara, J., and J. Caprio. 1996. Taste responses to binary mixture of amino acids in the sea catfish, Arius felis. Chem. Senses 21: 45-53.

Kubanek, J., J. R. Pawlik, T. M. Eve, and W. Fenical. 2000. Triterpene glycosides defend the Caribbean reef sponge Erylus formosus from predatory fishes. Mar. Ecol. Prog. Ser. 207: 69-77.

Lamb, C. F., and T. E. Finger. 1995. Gustatory control of feeding behavior in goldfish. Physiol. Behav. 57: 483-488.

Laurie, M. 1888. The organ of Verrill in Loligo. J. Cell Science 29: 97-100 (formerly Quarterly Journal of Microscopical Science). 
Lindberg, D. R., and W. F. Ponder. 2001. The influence of classification on the evolutionary interpretation of structure-a re-evaluation of the evolution of the pallial cavity of gastropod molluscs. Org. Divers. Evol. 1: 273-299.

Love-Chezem, T., J. F. Aggio, and C. D. Derby. 2013. Defense through sensory inactivation: sea hare ink reduces sensory and motor responses of spiny lobsters to food odors. J. Exp. Biol. 216: 13641372.

Lucero, M. T., H. Farrington, and W. F. Gilly. 1994. Quantification of L-dopa and dopamine in squid ink: implications for chemoreception. Biol. Bull. 187: 55-63.

MacGintie, G. E., and N. MacGintie. 1968. Natural History of Marine Animals, $2^{\text {nd }}$ ed. McGraw-Hill, New York.

Michel, W. C., and J. Caprio. 1991. Responses of single facial taste fibers in the sea catfish, Arius felis, to amino acids. J. Neurophysiol. 66: 247-260.

Michel, W. C., J. Kohbara, and J. Caprio. 1993. Amino acid receptor sites in the facial taste system of the sea catfish Arius felis. J. Comp. Physiol. A 172: 129-138.

Moynihan, M., and A. F. Rodaniche. 1982. The behavior and natural history of the Caribbean reef squid Sepioteuthis sepioidea. Adv. Ethol. 25: $1-151$.

Muncy, R. J., and W. M. Wingo. 1983. Species Profiles: Life Histories and Environmental Profiles of Coastal Fishes and Invertebrates (Gulf of Mexico): Sea Catfish and Gafftopsail Catfish. U. S. Fish and Wildlife Service, Division of Biological Services, FWS/OBS-82/11.5. U. S. Army Corps of Engineers, TR EL-82-4, 17 pp.

Nolen, T. G., P. M. Johnson, C. E. Kicklighter, and T. Capo. 1995. Ink secretion by the marine snail Aplysia californica enhances its ability to escape from a natural predator. J. Comp. Physiol. A 176: 239-254.

Norman, M. D. 2000. Cephalopods. A World Guide. Conch Books, Hackenheim, Germany.

Nusnbaum, M., and C. D. Derby. 2010a. Effects of sea hare ink secretion and its escapin-generated components on a variety of predatory fishes. Biol. Bull. 218: 282-292.

Nusnbaum, M., and C. D. Derby. 2010b. Ink secretion protects sea hares by acting on the olfactory and non-olfactory chemical senses of a predatory fish. Anim. Behav. 79: 1067-1076.

Nusnbaum, M., J. F. Aggio, and C. D. Derby. 2012. Taste-mediated behavioral and electrophysiological responses by the predatory fish Ariopsis felis to deterrent pigments from Aplysia californica ink. J. Comp. Physiol. A 198: 283-294.

Ogawa, K., T. Marui, and J. Caprio. 1997. Quinine suppression of single facial taste fiber responses in the channel catfish. Brain Res. 769: 263-272.
Pawlik, J. R. 1993. Marine invertebrate chemical defenses. Chem. Rev. 93: 1911-1922.

Prota, G., J. P. Ortonne, C. Voulot, C. Khatchadourian, G. Mardi, and A. Palumbo. 1981. Occurrence and properties of tyrosinase in the ejected ink of cephalopods. Comp. Biochem. Physiol. 68B: 415-419.

Roseghini, M., C. Severini, G. F. Erspamer, and V. Erspamer. 1996. Choline esters and biogenic amines in the hypobranchial gland of 55 molluscan species of the neogastropod Muricoidea superfamily. Toxicon 34: 33-55

Ruxton, G. D., T. N. Sherratt, and M. P. Speed. 2004. Avoiding Attack: The Evolutionary Ecology of Crypsis, Warning Signals and Mimicry. Oxford University Press, Oxford.

Sheybani, A., M. Nusnbaum, J. Caprio, and C. D. Derby. $2009 . \quad R e-$ sponses of the sea catfish, Ariopsis felis, to chemical defenses from the sea hare, Aplysia californica. J. Exp. Mar. Biol. Ecol. 368: 153-160.

Sorensen, P. W., and J. Caprio. 1998. Chemoreception in fish. Pp. 375-406 in The Physiology of Fishes, 2nd ed., R. E. Evans, ed. CRC Press, Boca Raton, FL.

Staudinger, M. D., and F. Juanes. 2010. A size-based approach to quantifying predation on longfin inshore squid (Loligo pealeii) in the northwest Atlantic. Mar. Ecol. Prog. Ser. 399: 225-241.

Staudinger, M. D., R. T. Hanlon, and F. Juanes. 2011. Primary and secondary defences of squid to cruising and ambush fish predators: variable tactics and their survival value. Anim. Behav. 81: 585-594.

Voss, G. L. 1963. Function and comparative morphology of the funnel organ in cephalopods. P. 74 in Proceedings of the XVI International Congress of Zoology, Vol. 1, J. A. Moore, ed. Washington, D.C. (Abstract).

Williams, L. W. 1909. The Anatomy of the Common Squid, Loligo pealii, Lesueur. E. J. Brill, Leiden, Holland.

Wood, J. B., K. E. Pennoyer, and C. D. Derby. 2008. Ink is a conspecific alarm cue in the Caribbean reef squid, Sepioteuthis sepioidea. J. Exp. Mar. Biol. Ecol. 367: 11-16.

Wood, J. B., A. Maynard, A. Lawlor, E. K. Sawyer, D. Simmons, K. E. Pennoyer, and C. D. Derby. 2010. Caribbean reef squid, Sepioteuthis sepioidea, use ink as a defense against predatory French grunts, Haemulon flavolineatum. J. Exp. Mar. Biol. Ecol. 388: 20-27.

Yang, H., P. M. Johnson, K.-C. Ko, M. Kamio, M. W. Germann, C. D. Derby, and P. C. Tai. 2005. Cloning, characterization, and expression of escapin, a broadly antimicrobial FAD-containing L-amino acid oxidase from ink of the sea hare Aplysia californica. J. Exp. Biol. 208: $3609-3622$.

Young, R. E., and K. M. Mangold. 2000. Cephalopod pseudomorph function. [Online]. Tree of Life Web Project. Available: http://tolweb. org/accessory/Cephalopod_Pseudomorph_Function?acc_id=1964 [2013, November 12]. 